American Journal of Applied Sciences 8 (3): 290-296, 2011

ISSN 1546-9239

(C) 2010 Science Publications

\title{
Modeling of Multi-Level Capacitated Lot-Size Scheduling Problem
}

\author{
Zuhaimy Ismail, Diyana Abd Mahad and Tan Siew Ching \\ Department of Mathematics, Faculty of Science, Universiti Teknologi Malaysia, \\ 81310 UTM, Skudai, Johor, Malaysia
}

\begin{abstract}
Problem statement: Lot-size is the clustering of items for transportation or manufacturing processes occurring at the same time. The issue in lot-size problem is to design production processes so that the feasible production quantities are equal to customer demand quantities and the timing of production is such that inventory positions are almost zero. Approach: In this study, we explore the multi-level lot-size and scheduling problem. It is on a multi-level capacitated lot-size problem or known as the multi-level lot-size problem with bottlenecks. Two models were introduced to solve the multi-level lot-size problem namely the Billington model and Alf Kimms model. Using these models, a simple heuristic method was designed to solve a multi level capacitated lot sizing scheduling problem. Results: In this study, we showed that Alf Kimms model is more efficient than Billington model. The result given by Alf Kimms model is always feasible without further modification unlike the Billington model. This is due to the way the constraint is devised to ensure the inventory balance. The constraint used in Alf Kimms model ensures that inventory in hand is always sufficient to fulfill the demand occurred in each period. However, the use of this constraint in Billington model is to ensure that the total production for each item is always greater than or equal to the total external demand in the time horizon. Therefore, without some form of modification, the result given by Billington model will be infeasible production plan. Conclusion: A comparative study between these models shows that both models were successfully devised to solve capacitated multi-level lot sizing problem with the objective function to minimize the total holding costs and setup- cost. This study also shows that the production schedule will always start at the last period because this will give the lowest costs and it also shows that Alf Kimms model gives a set of feasible sub-optimal schedule compare to Billington model.
\end{abstract}

Key words: Material Requirement Planning (MRP), lot-sizing problem, scheduling problem, integer programming, multi-level capacitated, sub-optimal schedule, cumulative demand

\section{INTRODUCTION}

Material Requirement Planning (MRP) is a production scheduling method to determine the demand for material required to produce a group of finished goods for multi-stage, or multi-product manufacturing system. In the MRP system, the lot-sizing problem arise a central issue to be addressed to the system designer. It is a problem, where the periods and the cost are fixed a priori. The multilevel lot-sizing problem is computationally a very difficult to solve as a NP-hard problem. Therefore, it is important to develop effective heuristics for these problems. Heuristics is a way one learn, discover or solve problems rather than guessing or acting at random. Therefore, the heuristics method presented here is based on integer programming develop by Billington et al. (1986) and Kimms (1997) when there is a bottleneck facility at workstations.
A workstation converts raw material into finished goods through the use of the resources in the manufacturing processes. A bottleneck can be a work center that limits the production rate of the entire system. The example of bottlenecks is, a machine with limited capacity, highly skilled or specialized workers and task-specific machines or tools, where, the capacity of the bottleneck is only slightly greater than demand over the horizon or the capacity is exceeded from time to time by demand (Singhtaun and Charnsethikul, 2010; Srichandum and Rujirayanyong, 2010; Abdullah et al., 2009).

Capacity supply is usually modeled as a function of time, stating the number of resource units available per unit time (Wong and Lee, 2009). The main problem for many firms is to decide how much they can produce with limited resources. Lot- sizing decisions are taken with respect to flow and storage of material and

Corresponding Author: Z. Ismail, Department of Mathematics, Faculty of Science, University Technology Malaysia, 81310 UTM, Skudai, Johor, Malaysia 
information. It combines the requirements and the production orders in the planning horizon. Furthermore, lot- sizing rules do not provide the correct period for placing the requirements but they determine the quantity of orders for a part or finished product (Yacouba et al., 2009; Vijay and Manoharan, 2010).

The basis in lot sizing is the trade-off between inventory and setups under consideration of the cost, service effectiveness and most of all, the holding cost. Holding Cost is the cost of holding item in storage and a Setup Cost is the cost that does not depend on the order quantity incurred whenever an order is placed during the planning horizon. Therefore, the objective of this research is to choose the lot-sizes, which will minimize the total setup and inventory holding costs. Matondang and Jambak (2010) Thus, in this study, we will consider a single level capacitated lot-size problem with a bottleneck facility (Abdullah et al., 2009; Rohini and Salivahanan, 2010; Hemamalini et al., 2010).

\section{MATERIALS AND METHODS}

The simple goods product structure can be decribed in Fig. 1, which is also known as Gozinto structure and known as a cyclic graph (directed network).

Figure 1 gives a general idea about product structure, a compact and easy to read. For example, there are 4 items as shown in Fig. 1; namely item 1 is the finish product that we want to produce. The ' $a$ ' in the graph is refer to the numbering of item $i$, 'b' refers to the number of item $j$ (predecessor item) needed in the production of one unit of item i (successor item). The procedure to produce an item 1 is divided into three levels, which is level 0 , level 1 and level 2, where level 0 indicate the final level, Level 1 is the intermediate level and level 3 indicate the first step to produce a product. In the process to produce finish goods, the raw material or resource is the most important. Therefore, this group will always take the lowest level (level 2). To purchase and prepare the row material is the most important work before the production is started. The arrows show that which item is the predecessor item to other. In Fig. 1, item 2 and item 3 are the predecessor items for item 1 . Meaning that, to produce one unit of item 1 needed one unit of item 2 and 3 (the number of unit predecessor item needed for the successor item is the blue number near the arrow.). There is another extension graph, which give us the same information, call Gozinto-tree (Fig. 2). It represents a directly revealed precedence relation in a feasible schedule that gained by converting the general Gozinto-graph into an assembly structure by copying nodes with more than one successor. The detail about Gozinto-graph has been discussed by Kimms (1997).
Figure 2 shows a multi-level/stage inventory system, system with connected set of stages representing the steps for assembly and/or distribution for a family of products. The general product structure can be split into the following 4 special cases namely the assembly; serial; parallel and single stage multi-item (Aly, 2009; Vijay and Manoharan, 2010). (Discussion on these cases will not be given in this study).

The mathematical model: Billington et al. (1986) formulated the lot sizing problem with bottleneck using integer programming with multiple capacity constraints. The inventory here is eliminated by substituting cumulative production minus cumulative demand and the integer programming model is given as follows.

Minimize:

$\mathrm{Z}=\sum_{\mathrm{j}=1 \mathrm{t}=1}^{\mathrm{J}} \sum_{\mathrm{j}}^{\mathrm{T}}\left[\mathrm{h}(\mathrm{T}-\mathrm{t}+1) \mathrm{q}_{\mathrm{jt}}+\mathrm{cs}_{\mathrm{j}} \mathrm{X}_{\mathrm{jt}}\right]$

Subject to:

$\left[\sum_{n=1}^{t} q_{j, n}-v_{j}-\sum_{i=1}^{t} a_{j i} q_{i n}\right] \geq \sum_{n=1}^{t} d_{j n}-I_{j o}$

$\mathrm{j}=1,2, \ldots, \mathrm{J} ; \mathrm{t}=1,2, \ldots, \mathrm{T}$

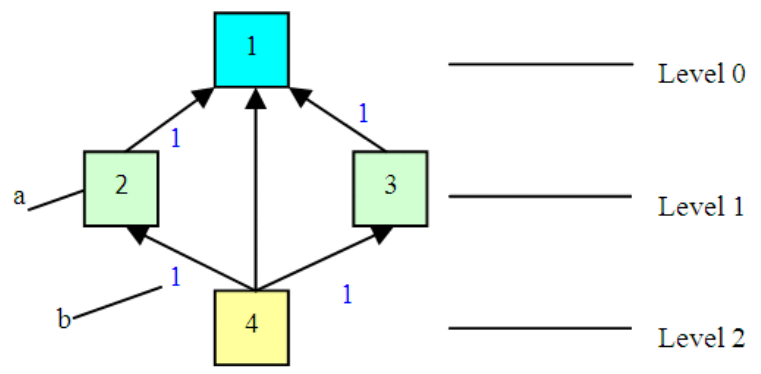

Fig. 1: A simple general product structure

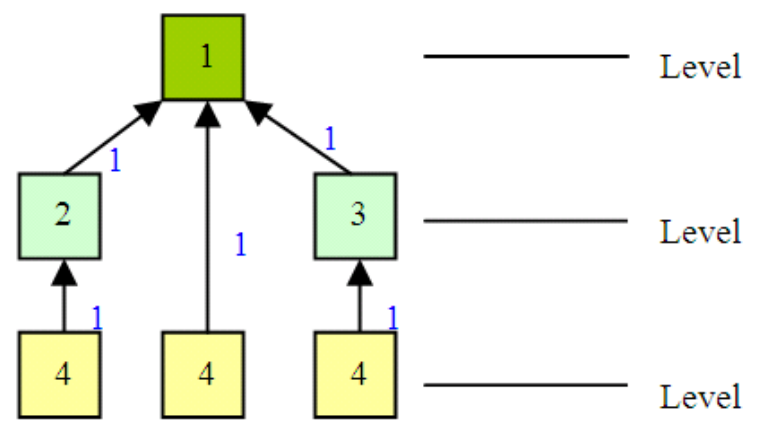

Fig. 2: A multi-level/stage inventory system 
Am. J. Applied Sci., 8 (3): 290-296, 2011

$$
\begin{aligned}
& \sum_{j=1}^{J}\left[b_{j 1} q_{j t}+s_{j 1} X_{j t}\right] \leq C A P_{t} \\
& l=1,2, \ldots, M, t=1,2, \ldots, T \\
& X_{j t}=\left\{\begin{array}{cc}
1 & \text { if } q_{j t}>0 \\
j=1,2, \ldots J & 0 ; \text { otherwise }
\end{array}\right. \\
& q_{j t} \geq 0 \\
& j=1,2, \ldots, J \\
& t=1,2, \ldots, T
\end{aligned}
$$

Equation 1 is the objective function for the problem. Note that, the effect of the inventory cost is included as a production cost that decreases linearly with time. Thus, production that is shifted earlier than its respective demand will incur a holding cost based on the value added and proportional to the number of periods in stock. Normally, the objective function in programming problem will include the labor cost but in our case, the labor cost is constant. Therefore we ignored it and the problem becomes a linear programming relaxation problem that can easily be solved. If not, the integer programming may not give the feasible solution for some problems and takes substantial CPU time. The main idea of this equation (objective function) is to find a trade-off between the holding and setup cost which minimize the total cost.

The second constraint (Eq. 2) is the constraint that makes sure the cumulative production minus cumulative requirements in period $t$ is always greater than or equal to the external demand in the planning horizon. It shows that, the production must be available at least $n-v_{j}$, where $v_{j}$ is the lead time. Then $\sum_{i=1}^{t} a_{j i} q_{i n}$ is the interrelation between the successor and predecessor items.

The third constraint is a capacity constraint for the bottleneck and ensures that setup cost and time are assessed only when there is production. Thus, the fourth constraint shows the setup cost and time is applicable only if there is a production run, $\mathrm{X}_{\mathrm{jt}}$ takes only value 0 or 1 . Such a charge occurs when a production run to produce a batch of a particular product, $Q_{j \mathrm{j}}$, is undertaken and the required production facilities must be set up to indicate the run. It means that if there is no run of production for item $i$ in $t$ period, then the solution of $\mathrm{X}_{\mathrm{jt}}$ is 0 and will take the value 1 if it the run is there. The value $X_{\mathrm{jt}}$ is used to calculate the setup cost for the particular run of the production. Finally, constraint (5) ensures that $\mathrm{Q}_{\mathrm{jt}}$ is a non-negative decision variable.
Billington et al. (1986), presented a heuristic method based on Lagrangian relaxation embedded within a branch and bound procedure, for the multi-level lotsizing problem with a bottleneck. In their work, they proposed the solution into two phases, which are dual and primal procedures. Furthermore, they defined a sub problem by assigning a fixed value to some $X_{\mathrm{jt}}$ value at any node in the branch. Then relaxes all the capacity and all inventory balanced constraint for the production lot-size to solve it. Thus, a smoothing method is used to adjust the production in a primal phase and then they extend the primal phases to a dual phase, which yields modified setup costs and production in each period. Repeat the primal phase with these new prices and iterate until a good solution is obtained. The procedure of this heuristic will not be considered in study. In this study, we will study only the heuristic proposed by Wong and Lee (2009) to solve the problem modeled by Billington.

Kimms (1997) stated that there are a few basic assumptions needed from improving Ballington model. First, as we have already mentioned earlier, the demand may occur for all items including component parts. Secondly, the finite planning horizon is subdivided into a number of discrete time periods. The lead times should be a positive number, which are given due to technological restrictions such as cooling or transportation for instance. All items share common resources so may be all (some) of them are scarce. The capacities may vary over time. Producing an item requires an item-specifies amount of the available capacity and all data are assumed to be deterministic.

Items which are produced each period to meet some future demand must be stored in inventory and thus cause item-specific holding costs. Each item requires at least one resource for which a setup state has to be taken into account. Setting up a resource for producing a particular item incurs item-specific setup costs that are assumed to be sequence independent. However setup time is not considered. Once a certain setup action is preformed, the setup state is kept until other changes to the current state. Hence, some items produced having some idle time in-between; do not enforce more than one setup action.

As mentioned early, we consider the Capacitated Lot-Sizing Problem (CLSP). It was a problem with many items produced per period. Therefore, we need to derive the model that takes into account the capacitated condition. Alf Kimms proposed an integer programming formulation for the CLSP problem, which we will used to compare the result given by Billington model and by the heuristic method. 
Am. J. Applied Sci., 8 (3): 290-296, 2011

The lot sizing in MRP only becomes realistic when features such as capacity constraints and the fact that systems are multi-level can be incorporated into the model. Muhammad and Jambak (2010), reviewed and added to contributions made to this area. Simultaneous lot sizing and capacity requirements planning in an MRP framework had been provided in their work. We proposed the adaptation of simple heuristics as developed by Toklu and Wilson and modify them to satisfy the problem requirements. The production items are divided into the end item and the non-end items. Fig. 1, gives a general production system. The production of each non-end item is unconstrained and so has neither any effect on the production of any other non-end item nor the production of items which are constrained by the bottleneck. As demand for of all items is known in advance, the production decision for each no-end -item becomes a relatively simple one of when to produce in order to minimize the contribution to costs (holding and setup costs) of each non-end-item. The fact that demand for end-items determined the demand for intermediate items does not invalidate the independence of the production of each item as demand for end-items is known several periods in advance. The extension to dependent product item cases for different product structures is an area for further research. To determine when to produce end-items is more complex as these product items must share the resources of the bottleneck. Thus, for these items the production problem is a constrained problem. However, in general these items are in the minority.

Define $S_{\mathrm{jt}}$ as stock of product $j$ at start of period $\mathrm{t}$ and $\mathrm{P}_{\mathrm{jn}}$ as the quantities of product $\mathrm{i}$ at the end of period $t$.

Then:

$\mathrm{S}_{\mathrm{jt}}=\sum_{\mathrm{t}=\mathrm{n}}^{\mathrm{t}-1} \mathrm{P}_{\mathrm{jn}}-\mathrm{d}_{\mathrm{jn}} \quad \mathrm{t}=2,3, \cdots$

Where:

$\mathrm{S}_{\mathrm{j} 1}=\mathrm{S}_{\mathrm{j} 0}$

These items are the non-end items that are not produced under the bottleneck facility. For these product items the EOQ, the Silver-Meal and MRP approaches will be used. These approaches were chosen as they are comparatively simple to operate and in general will produce solutions of good quality.
Table 1: General MRP table

\begin{tabular}{llllll}
\hline & Periods & & \\
& - & & \\
Level i-item j & 1 & 2 & 3 & & \\
\hline Gross requirements & & & & \\
Opening stock & & & & \\
Net requirement & & & & \\
Start assembly & & & & \\
Schedule receipts & & & & \\
\hline
\end{tabular}

However, here we will only discuss the MRP approach used. The MRP table for each item at each level is shown as Table 1.

Assume that there is a bottleneck located in the intermediate level. i.e., bottleneck facility located in $3^{\text {rd }}$ item in 1-end-item problem. To deal with this kind of problem, note that the non-bottleneck items have been explained for different kinds of end-item problems. For this product item a simple heuristic was adopted which would adopt a greedy approach in production by having few setups, but with heavy utilization of the resultant production capacity. In addition, the heuristic would operate in a cyclic manner, moving between to produce reasonably smooth productions. The approach has broad similarities with the work of Singhtaun and Charnsethikul (2010) except that by excluding setup time and cost they handle a problem that is easier to solve. Abdullah et al. (2009), Yacouba et al. (2009) adopted a cyclic approach but do so by examining permutation schedules.

\section{RESULTS}

The heuristic is described with reference to three cases. However, in this study we will only discuss about two of the cases, which are 1-end-item problem and the 3-end-item problem.

Case (a) 1-non-end-item problems: Assume that there is one bottleneck located in the 2nd level in the product structure (Fig. 3), the heuristic is to which produce as much of non-end-item $\mathrm{j}$ as cap $\mathrm{t}_{\mathrm{t}}$ will allow in period 1 i.e. set $\mathrm{P}_{\mathrm{ji}}=\mathrm{cap}_{1}$, then produce $\mathrm{j}$ when stocks become negative if no production were made, i.e. find the next smallest $t$ for which $S_{j}<d_{j n}$. Continue the process of producing in each period $t$, which has this property.

$$
\begin{aligned}
& \text { If } P_{j n} \text { exceed } \sum_{t=n}^{T} d_{j t} \text { for any period } n \text {, then set } \\
& P_{j n}=\sum_{t=n}^{T} d_{j t} \text {. (If } P_{j n}>\sum_{t=n}^{T} d_{j t} \text {, then } P_{j n}=\sum_{t=n}^{T} d_{j t} \text { ). }
\end{aligned}
$$

Case (b) 3-non-end-item problems: Assume that the bottleneck is located at the 2nd level say in the product structure (Fig. 3.) and according to the heuristic; the first priority is in the first item in bottleneck facility in the structure, then the second item and so on. 


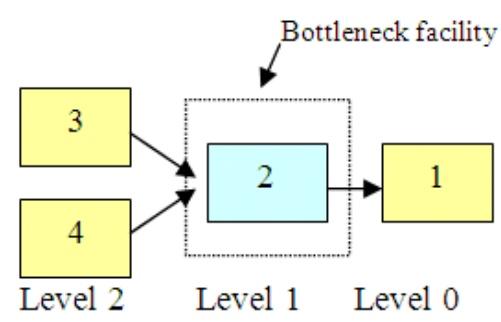

Fig. 3: The end-item product structure with 1 non-enditem inside bottleneck facility

The case study: A case study of a multi-level multi items problem will discussed. The values of the initial parameters are developed similarly to the set data used by Billington et al. (1986). A group of $\mathrm{N}$ items will be considered which are produced at a same production facility. The external demands are assume known for all end products and must be satisfied without backorders over a finite horizon of $\mathrm{T}$ periods with no external demand for components. Here we exclude the sequencing of production within the time period and the possibility of carrying over a setup cost between periods. The aggregate order size is constrained by a capacity limit. The objective is to find a lot-sizing strategy that satisfies the demands for all items over the entire horizon without backlogging and which minimizes the total cost of production run. This is the sum of the total holding and setup costs. All demands, cost parameters and capacity limits may be timedependent. Here we will recall the test problem and the result given using heuristic model derived by Billington model followed by the result given by $\mathrm{Al}$ Kim's model. Finally, some discussion about these two models is given.

Multi level multi item capacitated lot size problem with a bottleneck: Now, consider multi-level, multi items problem. The different between the single levelmulti item and multi level-multi item is that the later one has more than one level of product structure. This problem has only one bottleneck facility and one item produce in the bottleneck facility (item 2). Moreover, there is only one end item, which is item 1 . To produce one unit of item 1, it needed input of one unit of item 2. However, to produce one unit of item 2 it needs input of one unit of item 3 and 4 . The size of the items is J, let say $\mathrm{J}=4$ and $\mathrm{T}=5$ and the 'Gozinto' factor for this problem is to take the value, $\mathrm{a}_{21}=1, \mathrm{a}_{32}=1, \mathrm{a}_{42}=1$ and $a_{j i}=0$ for others. This means that, there are relationships for some items with some other items. For example, item 1 has relationship with item 2, where we needed one unit of item 2 to produce one unit of item 1 and so on. In this case, the maximum number each items $\mathrm{N}_{\max j}$ can be produced in each period are $\mathrm{N}_{\max 1}$ is $50, \mathrm{~N}_{\max 2}$ is $50, \mathrm{~N}_{\max 3}$ is $50, \mathrm{~N}_{\max 4}$ is 50 . Assume that the initial inventory for all item are assumed to be zero and similarly for lead-time. The numbers of external demand exists for end items, i.e., $d_{12}$ is $10, d_{13}$ is 20 , d14 is 20 and $d_{15}$ is 10 . Furthermore, other parameters included in the production time of $\mathrm{j}$ unit item on the bottleneck facility, is $b_{\mathrm{j}}$. For example to produce one unit of item 2 is 1 minutes then $b_{2}=1 \mathrm{~min}$. Here we assume $b_{j}=1$ minutes, for $\forall j$ and the setup time, $S_{j}=1$ min for $\forall \mathrm{j}$, for the work centre for product $j$ in the bottleneck facility.

Suppose that, we set the holding cost for item $\mathrm{j}=1$, 2, 3, 4 as $0.5,2,1,3$ respectively, then we set the setup cost for item $\mathrm{j}=1,2,3,4$ as 50,100, 90, 200. Assume that the capacity utility is approximate by 90 percents. We assume that $\mathrm{CAP}_{\mathrm{t}}$ is available capacity of the work centre at time $t$, for $t=1,2 \ldots 5$, so let the capacity available for period $1, \mathrm{CAP}_{1}$ is 50 , period $2, \mathrm{CAP}_{2}$ is 50 , period $3, \mathrm{CAP}_{3}$ is 50 , period $4, \mathrm{CAP}_{4}$ is 50 and period 5 , $\mathrm{CAP}_{5}$ is 50 .

Here we found that, the limitation of the capacity exists in this problem and given that $\mathrm{v}_{\mathrm{j}}=0, \mathrm{v}_{\mathrm{j}}$ as is a positive and integral lead-time of item $\mathrm{j}$ or calls safety lead-time for product $\mathrm{j}$, for $\forall \mathrm{j}$. It satisfies the condition for a bottleneck problem that exited in a production line. This gives us a reason to suggest that this $\mathrm{v}_{\mathrm{j}}$ is a lot-sizing problem with bottleneck. Hence, in this problem $\mathrm{I}_{\mathrm{jt}}$ is the inventory for item $\mathrm{j}$ at the end of period t. Thus, $I_{j o}$ is the initial inventory for item $j$. Here, we assume that for all $\mathrm{j}=1,2 \ldots 4, \mathrm{I}_{\mathrm{jo}}$ is equal to zero $\left(\mathrm{I}_{\mathrm{jo}_{\mathrm{o}}}=0\right)$, meaning that there is on inventory in hand remaining from the previous periods before period 1 .

\section{DISCUSSION}

After developed the objective function and defined the variables of this problem, the system will carry on the iteration and provide the result to the result given as follows;

From Model (1): The quantity produced for each item in each period. Note that all items produced in period 4 and 5 only, such that $\mathrm{q}_{14}=10, \mathrm{q}_{15}=50, \mathrm{q}_{15}=50, \mathrm{q}_{24}=$ $11, \mathrm{q}_{25}=49, \mathrm{q}_{34}=10, \mathrm{q}_{35}=50, \mathrm{q}_{44}=10$ and $\mathrm{q}_{45}=50$. The empty space means, there is no production run in that period for certain item. This schedule is not logically and non feasible. In this case, the $X_{14}, X_{15}, X_{24}$, $X_{25}, X_{34}, X_{35}, X_{44}, X_{45}$ takes the value of 1 and the rest as 0 (the $X_{\mathrm{jt}}$ which taken the value 0 is show as the blank column). Thus the total cost is 1337 .

Heuristic method: Note that, the heuristic propose is use to find the sub-optimal solution for items which is produce in bottleneck facility. Therefore, the solution 
we obtain here is the solution for item 2 . The rest items in this case will solve using the approaches that we proposed in the previous chapter. Hence, in this case we were using the MRP approach to solve this problem. From Fig. 4, the structures of product have 3 levels, which are level 0 , level 1 and level 2 . Level 0 is referring to the final product and level 1 and 2 are referring to the parts. Thus the MRP Table 2 shows the analysis of the assembly of item 1 .

This Table 3 shows that the production run is started in period 2 to produce 10 units of item 1, 20 units in period 3 and period 4 . Then produce 10 units in periods 5. Note that we have obtained a set of schedule from the analysis before this. Therefore we consider the value obtain into MRP table for item 2. Thus it is shows as Table 3.

Figure 4, shows that to produce one unit of item 2 needed one unit of item 3 and one units of item 4 . These two items are at same level, which is level 2. Since, item 2 is start to produce in period 1 , we need to ensure that capacity of item 3 and item 4 are always sufficient in period 1 and also when there is a production run for item 2 in a certain periods. Thus, expand the assembly plan for item 2 into the gross requirements for item 3 and 4 . We need to produce 50 units of item 3 and 50 units of item 4 in period 1 . Then produced 10 units of item 3 and 10 units of item 4 in period 2 with the total cost of 2575.00

Table 2: MRP table for item 1

\begin{tabular}{llllll}
\hline & Periods & & & \\
Level 0- item 1 & ----------------- \\
\hline Gross requirements & - & 2 & 3 & 4 & 5 \\
Opening stock & - & - & - & 20 & 10 \\
Net requirement & - & 10 & 20 & 20 & 10 \\
Start assembly & - & 10 & 20 & 20 & 10 \\
Schedule receipts & - & 10 & 20 & 20 & 10 \\
\hline
\end{tabular}

Table 3: MRP table for item 2

\begin{tabular}{|c|c|c|c|c|c|}
\hline \multirow[b]{2}{*}{ Level 1- item 2} & \multicolumn{5}{|c|}{ Periods } \\
\hline & 1 & 2 & 3 & 4 & 5 \\
\hline Gross requirements & - & 10 & 20 & 20 & 10 \\
\hline Opening stock & - & 50 & 50 & 30 & 10 \\
\hline Net requirement & - & - & - & - & - \\
\hline Start assembly & 50 & 10 & - & - & - \\
\hline Schedule receipts & 50 & 10 & & & \\
\hline
\end{tabular}

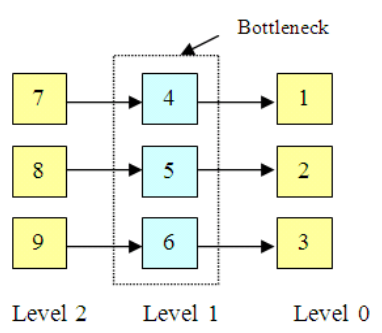

Fig. 4: A parallel product structure with 3 non-end item inside bottleneck
From model (2): The result obtained from Alf Kim's model shows the quantities produced for each items in each. It is found that for item 1 , the quantity $\mathrm{q}_{12}=16$, $\mathrm{q}_{13}=17, \mathrm{q}_{14}=17, \mathrm{q}_{15}=10$. Thus for item $2, \mathrm{q}_{22}=17$, period $\mathrm{q}_{23}=16$, q24=17 and $\mathrm{q}_{25}=10$. Then for item $3 \mathrm{q} 32=17$, $\mathrm{q}_{33}=17, \mathrm{q}_{34}=17$ and $\mathrm{q}_{35}=10$. There are two production run to produce item 4 , which is $\mathrm{q}_{41}=50$ and $\mathrm{q}_{45}=10$. The empty space means, there is no production run in that period for certain item. We have for item $1, \mathrm{I}_{12}=6$ and $I_{13}=3$. There is only one units of item 2 left, $I_{22}=1$ at the end of the period 2 during the entire time horizon. This situation also occurs for item 3 but it is at period 3, $I_{33}=1$. For item $4, I_{41}=50, I_{42}=33, I_{43}=17$. The empty space means, there is no inventory at the end of the period for certain item. The binary variable indicates that which item is setup in a period which takes the value of 1 and 0 . Thus, the total cost given by this model is 1667.50 .

\section{CONCLUSION}

Both models were devised to solve capacitated multi-level lot-sizing problem with the objective function to minimize the total holding costs and setupcost. This study shows that Alf Kim's model is more efficient than Belington model. The result given by Alf Kim's model is always feasible without further modification unlike the Belington model. This is due to the way the constraint is devised to ensure the inventory balance. The constraint used in Alf Kim's model ensures that inventory in hand is always sufficient to fulfils the demand occurred in each period. However, the use of this constraint in Belington model is to ensure that the total production for each item is always greater than or equal to the total external demand in the time horizon. Therefore, without some form of modification, the result given by Belington model will be infeasible production plan. The production schedule will always start at the last period because this will give the lowest costs, since the holding cost at that period is always the lowest compared to other periods. In this case Alf Kimms model gives a set of feasible suboptimal schedule compare to Billington model. The production plan that we get from the analyze is we need to produce 50 units of item 4 in period 1 , followed by 16 units of item 1, 17 units of item 2 and 3 in period 2. Next, produce 17 units of item 1 and 17 units item 3 and 16 units of item 2 in period 3 . Then 17 units of item 1 , 17 units of item 2 and 16 units item 3 in period 4 . Lastly, produce 10 units of each item 2, 3 and 4 to produce item 1 in the same period, with the total sum of production cost is 1667.50 . 


\section{REFERENCES}

Abdullah, M., M. Othman, H. Ibrahim and S. Subramaniam, 2009. Load allocation model for scheduling divisible data grid applications. J. Comput. Sci., 5: 760-763. DOI: 10.3844/jcssp.2009.760.763

Aly, W.M., 2009. Solving the state assignment problem using stochastic search aided with simulated annealing. Am. J. Eng. Applied Sci., 2: 703-707. DOI: 10.3844/ajeassp.2009.703.707

Billington, P.J., J.O. McClan and L.J. Thomas, 1986. Heuristics for multilevel lot-sizing with a bottleneck. Manage. Sci., 32: 989-1006.

Hemamalini, T., A.N. Senthilvel and S. Somasundaram, 2010. Scheduling algorithm to optimize jobs in shop floor. J. Math. Stat., 6: 416-420. DOI: 10.3844/jmssp.2010.416.420

Kimms, A., 1997. Multi-Level Lot Sizing and scheduling: Methods for Capacitated, Dynamic and Deterministic Models. 1st Edn., Physica-Verlag, New York, ISBN-10: 3790809675, pp: 355.

Matondang, M.Z. and M.I. Jambak, 2010. Soft computing in optimizing assembly lines balancing. J. Comput. Sci., 6: 141-162. DOI: 10.3844/jcssp.2010.141.162
Rohini, G. and S. Salivahanan, 2010. Optimal test time for system-on-chip designs using fuzzy logic and process algebra. J. Comput. Sci., 6: 12-17. DOI: 10.3844/jcssp.2010.12.17

Singhtaun, C. and P. Charnsethikul, 2010. Comparison of exact algorithms for rectilinear distance singlesource capacitated multi-facility weber problems. J. Comput. Sci., 6: 112-116. DOI: 10.3844/jcssp.2010.112.116

Srichandum, S. and T. Rujirayanyong, 2010. Production scheduling for dispatching ready mixed concrete trucks using bee colony optimization. Am. J. Eng. Applied Sci., 3: 7-14. DOI: 10.3844/ajeassp.2010.7.14

Vijay, J.F. and C. Manoharan, 2010. A comparative analysis of software engineering with knowledge engineering. J. Comput. Sci., 6: 1208-1211. DOI: 10.3844/jcssp.2010.1208.1211

Wong, L. and L.S. Lee, 2009. Heuristic placement routines for two-dimensional bin packing problem. J. Math. Stat., 5: 334-341. DOI: 10.3844/jmssp.2009.334.341

Yacouba, D., H. Guangdao and A.H. Abdulahi, 2009. Simulation planning for sustainable use of land resources: Case study in Diamou. J. Math. Stat., 5: 15-23. DOI: $10.3844 /$ jmssp.2009.15.23 